\title{
Toward An Evolutionary Theory of Human Capital
}

\author{
Carolina Cañibano \\ INGENIO (CSIC-UPV), Universidad Politécnica de Valencia, Spain \\ ccanibano@ingenio.upv.es \\ Jason Potts \\ RMIT University, Melbourne, Australia \\ jason.potts@rmit.edu.au
}

\begin{abstract}
.
The structure and dynamics of knowledge is central to modern evolutionary economics. In the canonical evolutionary model, knowledge exists in the routines and competencies of firms, an approach optimized to study industrial dynamics. In mainstream economics however, knowledge is represented as human capital, an investment by workers in education and skills, an approach suited to the study of labour markets, education, jobs and careers. Evolutionary economics has little to say about this. We propose a new research program for evolutionary economics that develops an evolutionary theory of human capital by representing human capital as a position on a network of knowledge and economic evolution as change in that network. Our new approach connects with the economic sociology of labour markets as networks; models the evolution of jobs as the dynamic structure of that network, and models a career as a path through that network; and furnishes a new theory of structural unemployment.
\end{abstract}

Keywords: economic evolution, human capital, labour markets, jobs, careers, employment JEL: B52, D1, E23, J00, M5, O3 


\section{This view of knowledge}

"There is grandeur in this view of life ... from so simple a beginning endless forms most beautiful and most wonderful have been, and are being, evolved." Charles Darwin, Origin of Species

The evolutionary view of economics focuses on knowledge, and its 'endless forms most beautiful and most wonderful' that since Veblen (1898), Penrose (1959), Boulding (1979) and Nelson and Winter (1982) have been conceived of as the habits, routines and institutions that are the 'economic genotype' to the observable economic phenotypes of commodities, resources and organizations. This view of knowledge is the foundation of evolutionary economics, which is ultimately a theory of the evolution of knowledge in economic systems, the primary locus of which-i.e. the carrier and replicator of knowledge - has been the innovating firm, shaped by entrepreneurial dynamics, in the form of competences and capabilities.

Yet a very differently centred approach to knowledge prevails in neoclassical economics, which since the work of Mincer (1958), Schultz (1961) and Becker (1964) has located knowledge - as human capital — as an investment good accumulated within individual economic agents. Evolutionary economists have long criticized the way this forces a treatment of knowledge as a commodity-like stock, rather than of knowledge as a structure or as a process (Loasby 2012). However, there are two overarching pay-offs to the neoclassical approach: first, simplified measurement by inputs (e.g. years of education); and second, tight connection to the study of labour markets, education, jobs and careers. In contrast, evolutionary economics - in which the analytic treatment of knowledge in firms has, since Schumpeter, been geared to the study of industrial dynamics - has comparatively little to say about such things. Perhaps the greatest lacuna of modern evolutionary economics is its relative neglect of the human capital domains of analysis of labour markets, education, jobs, careers and households. What is missing, in other words, is an evolutionary theory of jobs, careers, and households.

So how do we get there? In one sense, the basic shift required in the evolutionary approach is from a firm-centred conception of knowledge in the economy to an approach centred on individuals that is based on an epistemology of the economic agent as they acquire and use information and knowledge, in a social-institutional context. The challenge, of course, is to avoid the ontological collapse that Mincer- 
Shultz-Becker et al perpetrated when they developed the model of human capital as a metaphorical transfer from the physical capital of a firm, or macro-economy, that accumulates under investment (Mirowski 1989, 2009; Loasby 2008). In that approach, knowledge accumulates in the neoclassical agent just as physical capital accumulates in firms, namely by investment. To measure human capital, you sum the quantity of investment. Human capital is deferred consumption, an investment made in the expectation of higher future earnings in order to maximize the time path of consumption. Human capital investments (Schultz 1961) connect labour markets, education markets and final consumption markets through an optimized interdependent choice. The economic agent is now a "bundle of investments and skills sets" (Mirowski 2013). Human capital is commodified in the sense of being the outcome of a rational choice, as an intertemporal investment to maximize consumption through time. In competitive equilibrium, each agent optimally invests in human capital, given the agent's preferences, relative prices, and initial endowments. This conception of human capital as a private investment good furnishes the analytic foundation for neoclassical economics to then study labour markets, education markets, and household 'markets', including the economics of employment and careers.

A large domain of analysis is annexed with a simple but powerful metaphorical transfer. Can the same translation be done in evolutionary economics? Is it possible to model the human capital of the evolutionary economic agent-Homo Sapiens Oeconomicus (Dopfer 2005) - as the analogue of the routines and competences of the innovating firm? This has more or less been the default presumption, with the evolutionary microeconomic agent conceived as a behavioural complex of generic knowledge made of acquired rules, habits and routines. Yet this approach has many of the same limitations as the neoclassical model of human capital, namely it is also a cumulative investment model, differing only substantially in what is being acquired (habits and routines) and how (micro-trajectory) (Dopfer and Potts 2008). So, what would a first-principles evolutionary renovation of human capital theory look like?

Economic evolution means evolving knowledge (Loasby 1999) and, when viewed through the lens of human capital, can be seen as an evolving structure of knowledge onto which individual people locate themselves with respect to others through their discovery and adoption of particular rules and connections within an interconnected system of value (Potts 2000, Dopfer et al 2015). Firms and other 
organizations are predominant organisational and institutional features that organise this value, but they are also transactional containers that in an analytical sense obscure the underling structure of interconnected networks of human capital (Coase 1937). If you abstract from organizations and markets (and transactions costs), and just focus on networks of knowledge contained in individual people, what remains forms the elements of an evolutionary theory of human capital. In this view, what evolves in the process of economic evolution is not just technologies, firms and markets (Schumpeter 1942, Penrose 1959, Hodgson 1993, Nelson and Winter 1982, Arthur 2009), but also human capital, jobs and careers, now conceived as an evolving network of knowledge.

The Schumpeterian model emphasizes the process of creative destruction over firms, markets, commodities and industries, but evolutionary economists have tended to neglect the evolution of jobs. There are two basic questions: on the structure and dynamics of the evolution of jobs in an evolving economy, and on how human capital and jobs adapt and co-evolve, particularly over the life cycle of a skill/job (Vona and Consoli 2014). Our new approach will also address the theoretical implications of time, uncertainty, imagination and social learning and adaptation in the role of entrepreneurial discovery in an evolutionary reconception of the economics of individual professional careers. In neowalrasian models, a career is a sequence of jobs, the result of optimal investment in human capital, and assembled through labour market matchings. From the evolutionary perspective, however, a career is an imagination-led, experimentallyshaped, socially contextual pathway of discovery through an unfolding network.

Evolutionary economics normally locates knowledge in firms, which are then the analytic targets for the evolutionary processes of industrial dynamics (e.g. variation, selection, replication). From the same analytic foundations, a parallel line of argument is to conceptualise human capital and jobs as carriers of knowledge. Symmetric to a firm-centred view of economic evolution, with industrial dynamics at the meso level of analysis, is an evolutionary theory of human capital that is a job-centred view of economic evolution playing out as career dynamics at the micro level, and with employment and household demographic dynamics at the meso level. The firm-centred and job-centred views of economic evolution are not in competition. Both are consistent expressions of an underlying generic approach (Dopfer and Potts 2008) that differ with respect to the attribution of the carrier of knowledge. In Nelson and Winter (1982), the firm is the carrier, and each firm exists in a network of other firms. In our approach, the 
job is the carrier, and a job exists in a network of other jobs. The evolutionary theory of human capital is a corollary of the evolutionary theory of the firm.

\section{Human capital in economic ontology, analysis and theory}

Human capital, as the name implies, is a model built on a metaphor. That metaphor is that knowledge in a person is like the capital stock of a firm, or of a nation (Becker 1964). It is an input factor, the result of investment, the level of which is rationally chosen. But the metaphor elides a deeper recognition of human capital as the archetypical private good, indeed as Romer (1993: 72) explains "as close to a perfect good as one can get", endowed with the properties of rivalry, appropriability and excludability, and so with the necessary characteristics to be optimally traded and allocated in competitive markets. From this perspective, human capital, or embodied knowledge, requires no special consideration: it is just another economic good.

Yet this same starting point also permits an account of human capital as a special type of good, with public good-like properties that arise from the externalities associated with such private investment (Pigou 1920; Samuelson 1958), properties that are fundamental to models of economic development (Schultz 1990) and endogenous growth (Lucas 1988). Needless to say, such conceptualisations of human capital as a quasi-public good arising from its social or interactive dimensions entail the type of ontological contradiction criticized by Mirowski (2009) and Lawson (2013). There is no room for meaningful interaction in the neowalrasian model /framework because it is, by design, a framework of generalised interactions, each with all. The core of the neowalrasian framework is the axiom of completeness (Potts 2000, Loasby 2012). Yet if all agents are connected in an economic system, the system's behaviour may not be explained by certain selected connected structures. The concept of structure mattering, and therefore structural dynamics having explanatory content, is incommensurable with the axiom of completeness and the formal mathematical treatment of embodied knowledge in a field theoretic setting. For human capital to have explanatory component in a general equilibrium framework therefore requires that it have a commodity-like existence, as part of the endowment or resource set of the agent. Human capital, in other words, is specifically not a structure of interactions or connections between the agent and the world, it is not a node in a network, but rather is 
a quantity of a factor, the magnitude of which determines its generalised transformational effect across other markets. Human capital in this view is ultimately just another commodity, allocated by investment at the margin.

This real dimensioned conception of human capital-call it the cumulative approach-facilitates the further presumption that the accumulation of skills into people's minds and bodies is competitively translated into their efficient economic use, and that high-powered incentives to market rewards from human capital will similarly induce efficient levels of investment and supply. This view of knowledge encourages a public policy discourse in which cities and nations alike compete to accumulate talent by investment or incentive (Michaels et al. 2001, Kapur and McHale 2005). The cumulative approach prompts characteristic analytic lines of inquiry, such as the optimal human capital investment at the individual level (Becker 1964), at the public level (Mincer 1981), and as an efficient distribution of human capital at the macro level (Galor and Tsiddon 1997).

An early critique of the cumulative approach came form Boulding (1968: 113) ${ }^{1}$ who stressed that human capital "is a structure rather than an aggregate" and that its accumulation would not lead to an increased productive capacity unless new trained people fitted properly into production structures. Teece (2012: 530) similarly refers to the aggregative approach as "the naïve human capital thesis", arguing that human capital is not particularly valuable "unless employed cooperatively and deployed astutely", i.e. appropriately fitted into a functional structure. Indeed, to conceptualise any particular interactions as 'structure' we need an analytic framework in which human capital can be conceptualised in structural terms (Cañibano and Woolley 2015). ${ }^{2}$

The general theory of economic evolution is such a framework (Dopfer and Potts 2008). It is based on a distinction between generic and operant levels of economic analysis, in which the elementary particles of an economy are generic rules (these rules make possible economic operations such as production and consumption) and these rules evolve (Dopfer et al 2004, Dopfer 2005). People and firms are carriers of generic

\footnotetext{
${ }^{1}$ In his discussion of the economics of knowledge, Boulding refers to cumulative or reproductive processes as "printing" and to processes that trigger development and evolution as "organizing", implying the idea of "structure" (Boulding 1966: 5).

${ }^{2}$ The interdependencies between human capital and other productive assets are widely acknowledged in the literature. See the Oxford Handbook of Human Capital (Burton-Jones \& Spender 2012), section IV "human capital interdependencies", focuses on the complementarities between human capital and other elements of the firm such as "social capital" (Grant and Hayton, chap. 16), infrastructure and organizational capabilities (Teece, chap. 21) and information and technological assets (Burton-Jones and Burton-Jones, chap. 20).
} 
knowledge. In the evolutionary economic framework, an economy is made of generic rules $\mathrm{R}$. Each rule R has a population of actualizations. The generic rule framework distinguishes between three levels of evolutionary economic analysis: micro, meso and macro. Evolutionary economics is meso-centred, i.e. a rule and its population is a meso unit. Micro-analysis refers to the carriers of generic rules, which are the firms and agents, but also jobs, as an institutionally defined slot into which an agent fits. Macro analysis refers to the complex systems of meso. The micro-meso-macro analytic framework is underpinned by an ontological model (Dopfer and Potts 2004) called 'evolutionary realism' of three axioms that define the nature of existence from the evolutionary perspective. These are:

Axiom 1: bimodality, all existences are matter-energy actualizations of ideas Axiom 2: association, all existences are structures of association (with other existences)

Axiom 3: process, all existences are processes in time.

Following the standard Schumpeterian/Nelson-Winter approach to evolutionary economics, Dopfer and Potts (2008) translate these three axioms into an analytic framework centred on firms in which: (axiom 1) firms are carriers of knowledge; (axiom 2) firms are structures of knowledge, and the associations between rules determines the capabilities the firm has; (axiom 3) firms are processes of knowledge, and can learn and change through time.

The same line of reasoning can also be applied to a human capital or job-centred view of knowledge in which:

Axiom 1: jobs are carriers of knowledge

Axiom 2: jobs are structures of knowledge, the associations between the rules the agent carries and those of other agents determines the capabilities the job has Axiom 3: jobs are processes of knowledge, becoming more or less complex through time

The evolutionary approach is consistent with an analytic representation of human capital in which it is jobs (rather than firms) that are the carriers of knowledge and locus of economic evolution. The axiomatic approach is also consistent with human capital as carrier-specific specialised knowledge that is the product of a micro trajectory of 
learning and adoption in which each carrier (job) will contain some overlap in terms of rules common to other carriers (jobs), so forming a meso unit (a type of work).

Furthermore, the knowledge that an agent carries will change over a lifetime, not only because of their own adoption and retention of new meso rules, but because of the adoption and retention of rules by other agents with whom they are connected, whether within a firm (hierarchical association) or market (contractual association) or other institution. Human capital does more than just accumulate, as in the mainstream model, but also evolves through changes in origination, adoption and retention of meso rules as change in the associational and process structure of the economic order.

Human capital, in other words does not just accumulate, it evolves. But it does not evolve at the level of the micro individual (that makes no sense from an evolutionary perspective, just as it makes no sense to speak of a firm evolving) but rather at the meso (population) level of the complex network of interconnected knowledge.

\section{Evolutionary human capital: the network perspective}

Neoclassical human capital is a vector of inputs, but evolutionary human capital is analytically represented as a node in a network that is 'relational and processual' (Lawson 2015: 28), and ontologically grounded as an associational structure of complementarity. ${ }^{3}$ Yet many possible theoretical models are consistent with this, and different disciplinary foundations suggest different ways to represent an evolving structure of human capital.

\subsection{A simple network (sociology)}

Michel Callon's (1991) socio-economics of a "techno-economic network" is a useful base to conceptualize human capital as networked. In particular, consider Callon's (1991: 138-9) conceptualization of skills as genuinely complex systems:

Embodied skills may also be treated as networks of entities.... The division between

\footnotetext{
${ }^{3}$ Complementarity plays a central role in evolutionary economics. One of the building blocks of evolutionary realism (Dopfer and Potts 2004) is the conceptualization of existence as inherently and naturally connected and of knowledge as necessarily distributed (Dopfer 2005). A theory of economic evolution is a theory of the reconfiguration of connections (Loasby 2001) and therefore a theory of complementarity (Dopfer et al. 2015).
} 
context and content disappears. No description of skills is possible unless the networks of humans, texts and machines within which they are expressed and put to work are reconstituted. ... To describe a skill is thus, at the same time, to describe its context.

In Callon's theory, the level of complementarity and fitness between the network's components is approached by the concept of 'convergence', which the network achieves by means of 'coordination' and 'alignment', meaning 'the way in which the activities of actors fit together despite their heterogeneity" (ibid, 148). Networks are described by their strong or weak convergence at a certain moment of time, and by their evolution towards stronger or weaker convergence over time. For example, in a weakly convergent network "we find workers who do not want to play the role defined for them by the machine" (ibid, 144). In contrast, in a convergent network,

"each actor is able to identify and mobilize the skills within that network without having to get involved in costly adaptation, translation or decoding. In a totally convergent network each actor would have specific skills but everyone else would know how to use them. ... Strongly convergent networks only develop after long periods of investment, intense effort and coordination" (ibid, 148).

The axiom of completeness in neowalrasian economics implies - in Callonian terms - perfect convergence of all productive networks. ${ }^{4}$ In an evolutionary ontology, in contrast, the Callonian concepts of 'alignment' 'coordination' and 'convergence' have analytical meaning. For our purpose, it is useful to visualize human capital as a structure formed by the networked knowledge carriers that Callon selects to explain the replication of knowledge. These are texts, technical objects and embodied skills (Callon 2002: 289). Figure 1 below illustrates a simple conceptualization of musical embodied skills as networked with the corresponding complementary scripts, instruments and skills. The level of alignment and coordination between these elements results in the differentiated quality (value) of the music performed by the network (orchestra, band).

\footnotetext{
${ }^{4}$ Interestingly, the ontology of evolutionary economics (Dopfer and Potts 2004, Potts 2010) is commensurable with Callon's theory, allowing us to reflect on the components and connections that form human capital structures.
} 


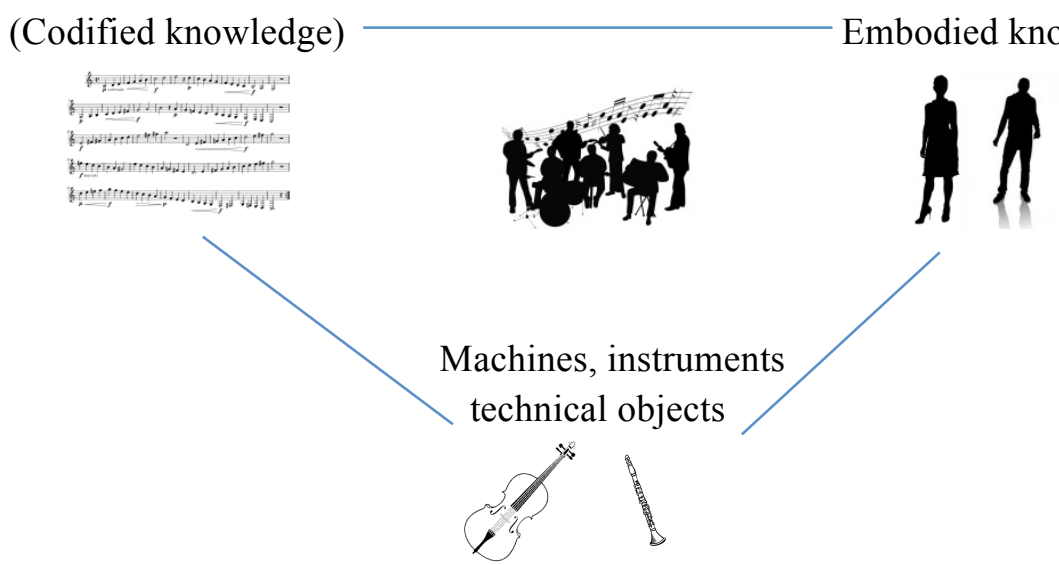

Figure 1: Human capital as a network (Callon)

\subsection{A complex topology (network theory, evolutionary economics)}

In the complexity theory approach to evolutionary economics, an economic system is a complex structure of connections between elements (Potts 2000, Dopfer and Potts 2008). An economic system, at any level or scale of analysis, can be mapped to a complex topology (a topographical hyperstructure) as 'a system in state-space' (Potts 2000: 61; Elsner et al. 2015: 254). A human capital network can be conceived in the same way, mapping to an abstract network topology, e.g. in an NK model in latticespace $Z^{n}$, where $\mathrm{N}=$ number of nodes, $\mathrm{K}=$ average connections per node. Analysis then considers the geometry of that network topology, bounded between extremes of a random network (random probability of nodes being connected), and a complete network $(\mathrm{K}=\mathrm{N})$. A working hypothesis for the geometry of human capital networks that they are likely similar to other evolved networks, being both clustered, in the sense of tight local groupings with weak global connections (Watts and Strogatz 1999), and complex, in the sense of being poised in a narrow window of state-space between order and chaos (Kauffman 1994).

In a network topology view of human capital, the properties and qualities of human capital are represented in the geometry of the network, and changes in human capital are changes in the geometry of the network. Clusters and other dense topological features map to emergent value creation, whether deliberately designed (within a firm) or self-organizing (an industrial district). Compact ordered networks of human capital are assumed to exist within a wider network flux of random connections, with the whole 
system tending under evolutionary forces toward the complex regime of state-space at the boundary between order and chaos. ${ }^{5}$

\subsection{Emergent complex networks (complexity economics)}

An evolutionary human capital network is a complex adaptive system, like other complex adaptive systems. It is a bounded but open system, spatially and temporary located. It is connected to an environment of other systems, with which it exchanges resources of value (energy and knowledge). It exhibits non-linear but path-dependent irreversible trajectories. It is endowed with the capacity to adapt, learn and transform; it is self-organized, since its structure may change spontaneously without external stimulus or pressure. Analysis of individual components of human capital as a network does not translate to understanding the behaviour of the system (Prigogine and Stengers 1979, Prigogine 2005, Saura 2003) because of its emergent complexity. But how complex is an evolving human capital network?

Foster (2005) classifies complex systems by distinguishing four different orders of complexity. He distinguishes first and second order complex adaptive systems in physio-chemical and biological settings from higher order complex systems where human beings are incorporated as actors and where knowledge also exists as mental models (Boulding 1961), as representations of reality (Loasby 2001) that derive from experience and imagination (Shackle 2010). The interaction of mental models with the natural environment gives rise to third-order complex systems, and the interaction of mental models with other mental models gives rise to fourth-order complex systems (Foster 2005, 877).

Human capital networks are in this sense mainly third- and fourth-order complex systems, where agents deploy their knowledge and skills in a localized context and in connection with the material and natural environment, but also in connection with the representations of the world, aspirations, plans, attitudes and complementary skills of other agents. At this level of complexity the recombination of ideas and the emergence of novelty are sources of change and evolution, where new ways of combining embodied skills with material objects and other forms of knowledge, as well as new ways of connecting with hierarchically superior systems, may always be imagined. As

\footnotetext{
${ }^{5}$ In this model, we would expect the total network of human capital to have a power-law distribution (Barabasi 2001), and that rather than a pooling model of job-creation and job-destruction in standard separation and matching models, we would instead propose an evolutionary model of employment dynamics based phase transitions.
} 
third order complex systems, human capital networks evolve through new skills and capabilities. But as fourth-order complex systems, human capital networks evolve through imaginative conjectures about new connections and their interaction with other such conjectures.

\subsection{Upward and downward complementarity (evolutionary economics)}

Dopfer et al (2015) define economic evolution as a 'process of generic change in economic connections' where complementarity establishes connections. They distinguish between "downward complementarity" and "upward complementarity" where the former proceeds by 'division, differentiation and reorganization' and the latter by "new combinations and cross-fertilization". Downward complementarity is 'essentially Smithian and Marshallian' and results in the reorganization of 'wholes into new parts', whilst upward complementarity is 'essentially Schumpeterian' turning 'parts into new wholes' (Dopfer et al. 2015: 3). The evolution of human capital networks involves changes in both upward and downward complementarity.

As above, evolutionary human capital networks are conceptualized as adaptive, third-and fourth-order complex systems operating in a certain spatial and temporal context, where individual embodied knowledge is connected to other complementary resources, such as codified knowledge, machines and other technologies, and knowledge embodied in other people. The specific structure of connections between these elements defines the nature of jobs and occupations. The complementarity between the different resources forming the human capital system may be downward or upward. Downward complementarity results from progressive labour division and knowledge specialization. Increasing levels of specialization and sub-division of tasks lead to the emergence of more complex human capital networks, where highly specialized skills are coordinated with complementary knowledge carriers. Upward complementarity results from recombination and cross-fertilization among potential human capital network components. A new association of a set of skills with a new technology may generate a new human capital network, defining a new set of occupations. An example is the new association between molecular biology and computer science, giving rise to the new field of bioinformatics and the emergence of new jobs such as computational biologists and bioinformatics computer scientists. 
Since the structure of complementarity between a set of components defines a job, changes in both the set of networked elements and in the connections among them imply changes in the nature of jobs and occupations. Goldin and Katz (2008: 122), who examine the dynamics between new technologies and new jobs, find that technologyskill complementarity is associated with the emergence of new production methods. Similarly, Vona and Consoli (2014) conceptualize the change in the skill content of occupations that follows technological breakthroughs as an evolutionary process where skills are complementary to the technology and subject to progressive adaptation supported by educational institutions. The blending between human and machine intelligence in the redefinition of modern occupations has also been stressed by Cowen (2014) who observes growing economic rewards from the machine-human cooperation.

These four different models of network structure and dynamics-(1) sociological techno-economic networks; (2) topological complexity; (3) emergent complexity; (4) and upward and downward complementarity-all propose different analytical approaches that illuminate different analytic aspects of an evolutionary model of human capital. There are certainly other models too that might be developed, but these sufficiently illustrate some plausible analytic starting points that might be developed toward theory and empirics.

\section{A career is a path through an evolving network of jobs}

In our new evolutionary approach to human capital, what evolves in an evolving economy is a network of knowledge that can be identified at each locus as the evolutionary dynamics of jobs. Jobs evolve, both as a 'species' of any particular job that follows an evolutionary (meso) trajectory and can be measured as a population by the number of people with that job. But from the micro perspective of each individual agent, examined through time, jobs are interlinked stations in a more individually meaningful concept of a career.

A career is also an evolutionary meaningful object because it adds to the micro account two temporal (path in a network) and imaginative (third- and fourth order complex) components: uncertainty and imaginative and strategic intentionality (Muñoz et al. 2011). The problem with the neowalrasian approach to human capital is that it limits conceptualisation of a career to a sequence of jobs, education and reputational investment, and the outcome of labour market matching. However, influential work on 
careers has been developed in a number of other fields, including sociology, management, psychology and organisational science. There is a distinct conceptual shift in contributions to career theory from approaches that stress mainly the cumulative and sequential nature of careers to more recent developments that emphasize their openness and subjection to uncertainty. Early sociological models of careers (Dalton et al 1977) defined sequential career stages of individual progress as they accumulate knowledge and build the differentiated capabilities and psychological attitudes necessary to assume the corresponding roles at each career stage. A career is conceived as a more or less well-defined path. Subsequent career theory sought to account for the declining significance of single organisations and industries and of consistent main roles as the basis for understanding careers (Arthur 1994). Several key concepts have been developed to cope with more flexible careers that span different organisations, industries and roles such as the idea of the "protean career" (Hall 1996) that stresses the role of adaptation to change, and the "boundaryless career" (Arthur and Rousseau 1996) as a career that moves across organisations and settings. Career theory has incorporated uncertainty and the need for adaptation to change. In addition, a developing area of career theory attempts to conceptualise the tension between the agency and the constraints imposed by institutional conditions to explain individual career decisions (Tams and Arthur 2010, Woolley et al. 2016).

Evolutionary economic theory offers tools and concepts to systematize and develop these ideas further and to address their economic implications. First, from an evolutionary perspective, a career is path-dependent. It is a learning process throughout which the individual accumulates experience and capitalizes on different types of acquired knowledge which condition her opportunities and choices. Second, since human capital is conceptualized as networked, a career is a path through a network of connections (interdependencies) which transforms itself over time. Third, the time horizon for evolution is open and the economic agent-Homo Sapiens Oeconomicus (Dopfer 2005) - is endowed with the capacity to learn and to imagine future scenarios and act with respect to them. This implies an analytical conception of careers not only as 'unbounded' or learning and adaptation pathways but also as genuine discovery processes. 
"La vida consiste en hacerse lo que se es"

(Life consists in becoming what one is)

Jose Luis Sampedro, El Rio que nos lleva

Evolutionary microeconomics is analysis of how individuals create, acquire, and use generic knowledge (Dopfer and Potts 2008). An evolutionary microeconomics of human capital should address how individuals originate and adopt knowledge about their skills and capabilities, and how they use this knowledge productively to interact with other knowledge carriers. Which is to say it is not a theory of the choice to invest in their human capital, but rather a theory of the higher-order choice to decide that they need to change their human capital, to figure out what human capital they then need, including what they need to decouple from, and from where to source that and how. This is analogous to the R\&D decision in the innovating firm.

The standard simplifying assumption is that the neoclassical economic agent has complete information about the productive utility and market value of the knowledge they carry and have invested in acquiring. They have knowledge about their own knowledge, i.e. its marginal revenue product, and importantly, so do others. But, in any situation but a static environment, the evolutionary economic agent has no such information about their own human capital. In a changing environment, their problem is uncertainty about the value of the knowledge they have. This problem is both local and global. The same skills may be equally or more valued elsewhere, or in different configurations, or the change may be temporary, or the human capital may be devalued, requiring adaptation. But this is also not a unique problem to change, for it begins with every economic agent, born ignorant of innate potential and capabilities, and through which economically valuable capabilities must be discovered, often through experimental learning, and with continual feedback from labour market prices. This process is social and contextual. Differences in contexts and interactions may trigger different paths of self-discovery. Similarly, our own knowledge of our own knowledge is imperfect and contextual. We therefore tend to look to what others with similar human capital are able to achieve, and at what cost, and how markets and society rewarded them. Learning the value and opportunities of your own human capitalknowledge about your own knowledge - is an experimental and social process. 
Human capital may be conceptualized as self-discovery in a similar way to how Hausmann and Rodrik (2003) modelled economic development, as a learning process of self-discovery of comparative advantage. Entrepreneurial self-discovery theory recognises that the discovery of economic opportunities, i.e. what can be profitably produced in particular settings is a quasi-public good, as this discovered information confers externalities upon other entrepreneurs. Indeed, Hausmann and Rodrik's point is that this information about the entrepreneurial opportunity, which gathers local information about costs and global information about demand, has the properties of a public good, and is therefore a source of entrepreneurial failure because of the market failure problem of discovering that information. Mutatus mutandus, the same argument applies to careers, which can also be modelled as a learning path of experimental discovery, and which also have the same 'who goes first' quasi-public good problem. Career paths are like entrepreneurial opportunities, in that the rewards are to those who move early, but not to those who move first, because they incur all the costs of that discovery. So there is a collective action problem in career discovery. How is this resolved?

One way is from population diversity, in which different people have different risk preferences regarding self-discovery and job-discovery. Those who do invest in discovery create benefits for themselves by their entrepreneurial actions in exploring and exploiting the space of human capital (Cañibano et al. 2006; March 1991, Dopfer et al. 2015), but in doing so they also create benefits for others, by discovering and revealing information. But pure exploration is a costly, risky strategy, and a more risk neutral strategy will follow well-known career ladders with progressive accumulation to remain within stable networks of knowledge. While individually rational, this generates no discovery, and no public value. In contrast, an explorative rather than exploitative strategy would 'switch networks', potentially discovering new connections of skills that make for new combinations of value, as new jobs.

Exploit /explore preferences will be individually specific in each context. The decision to explore new networks will require not only successful discovery but also adaptation, alignment and network convergence. New job discovery is individually costly, fraught with failure, and yet crucially important aspect of economic evolution; just as with the entrepreneurial founding of first firms. 
A 'job' is redefined in this process as a skill set moves into a different context. Callon's socio-economics of knowledge is again useful here to conceptualize the state of networks according to the level of consolidation of the knowledge they carry. In consolidated networks 'competences and instruments have been duplicated in multiple copies and widely distributed' (Callon 2002: 290). Similar copies of the same network may be found in multiple locations and the knowledge regarding the functioning and complementarities operating in such networks are also widely distributed, thus facilitating the process of adaptation and convergence of the skills carried by agents moving into or between such types of networks. Individual skills circulate and reproduce more easily across consolidated human capital networks (Woolley and Cañibano 2010, 17). In contrast, in ‘emergent networks' (Callon 2002) knowledge concerning their forming components and complementarities barely exists. If it does, it is highly localized and not yet distributed. The number of agents sharing the use of common sets of skills, and other forms of knowledge (i.e. codified knowledge and instruments) is limited (Woolley and Cañibano 2010: 17). Someone moving into such a network will experience a longer and more uncertain adaptation process. Yet, the process has social value since it will generate knowledge regarding the properties and complementarities of the network that others may then use to reproduce the network in different locations and contexts, so generating a positive externality. A purely emergent network reveals information to other agents with similar skills about the opportunity to work in a particular new environment. First movers into a new career or job opened up by economic evolution generate valuable information for those that follow. Discovering a job is thus homologous to Hausmann and Rodrik's conception of the entrepreneurial problem of niche discovery. ${ }^{6}$

This evolutionary human capital approach enables us to study the process of job origination, adoption and diffusion and retention just as we study technological trajectories. It highlights the social benefit from individual acts of self-discovery, as a positive information externality. It is sometimes presented in industrial dynamics that new technologies create new industries, which in turn creates new jobs (e.g. software

\footnotetext{
${ }^{6}$ It is important to emphasise that our conception of 'job discovery' is very different to the job search (or search and match) literature, which is both an economics of information and a mechanism problem. Search theory (Mortensen 1986) supposes that the matching problem in labour markets (a two-sided market) is finding a job that already exists, and thus the problem is one of optimal search. Job discovery is a different problem, because the job does not exist, but just be mutually discovered - by both employer and employee - as a combination of skills and connections that yields value.
} 
engineer, social network marketer, bioinformatics). But someone must go first into those careers. They must leave an existing career. In doing so they generate information about the value of the opportunity to others. This is an under-examined consideration for both economic evolution and for public welfare.

\section{Evolutionary economics of structural unemployment}

Unlike the natural rate of unemployment, which can be explained with search and match models, structural unemployment is more difficult to understand from within the neoclassical framework, requiring variously: labour market frictions (e.g. wage floors); complementary market constraints (e.g. housing market frictions preventing relocation, education or financial market frictions preventing retraining); behavioural phenomena (e.g. identity economics, myopia); interdependence (e.g. household economics); or complex institutional interactions (e.g. welfare, occupational licencing, tax policy, and so on). But from the evolutionary perspective structural unemployment is not a market failure problem, in the sense of a price coordination problem resolved with the right prices (deregulation), or appropriate transfers to correct for the wrong prices (policy). It is also not an aggregate demand problem, resolved with stimulus. Rather, structural unemployment is a consequence of new technologies (more broadly, new generic rules) changing the connective structure of technologies (associations between generic rules), and thus the opportunities for value creation. Physical capital and material resources can be depreciated, scrapped, resold, recycled, refurbished, unbundled and re-bundled and so on, constrained only by transactions costs. This is manifestly not true of human capital, which is less fungible and more path dependent. ${ }^{7}$ The concept of structural unemployment recognises that the adjustment process in human capital can get caught in traps.

The evolutionary perspective on human capital conceives of these as knowledge traps, not resource or incentive traps per se. The resolution is the discovery of new knowledge, which is fundamentally an entrepreneurial experimental process to discover new sources of value through new connections. The resolution of structural unemployment comes from the re-coordination between human capital and other

\footnotetext{
${ }^{7}$ Note that this does not happen at the origin of a new technology (meso 1), but rather in the mature phase of a new generic rule (meso 3 ) in the operational level as efficiency and productivity gains are driven through the population releasing resources, both physical and human capital.
} 
resources through mutual entrepreneurial actions of discovery (Dopfer and Potts 2008). This occurs as people with devalued skill bundles and connections seek to discover new uses for those skills and connections, including particular re-bundling or recombinations (i.e. investing in new skills), while at the same time those with complementary skill bundles and resources seek opportunity in reintegrating these. The resolution of structural unemployment is an evolutionary process that unfolds over a micro-meso-macro trajectory with distinct phases of de-coordination and recoordination of human capital bundles and connections.

This evolutionary perspective emphasises that the resolution of structural unemployment is at base a knowledge problem at the level of the agent. The discovery or new or different uses for existing skills is a knowledge problem, but so too is retraining and investment in education when the focus is put to what specific type of training and education is sought. This knowledge process requires the de-coordination (what connections need to be removed) and re-coordination (what connections need to be added) of human capital, a process that is inherently subjective, contextual and embedded, in that the agents themselves will be best positioned to solve these problems, provided they are not constrained from doing so. But structural unemployment, understood as a discovery problem, is also a collective action problem with social learning, in the sense that agents can learn from other agents' experiments about particular de-coordination and re-coordination within the human capital network. What the evolutionary human capital perspective highlights is that structural unemployment can be reframed as a species of knowledge coordination problem, and so policy solutions may be similar to other such species of knowledge coordination problem, such as in innovation policy (Bakhshi et al 2011).

\section{Conclusion}

This paper has sought to inquire into the value and prospect of developing an evolutionary economic theory of human capital, and with three distinct motivations. First, a lacuna in Schumpeterian evolutionary economics, in which the knowledge in an economy - and therefore the answer to Kenneth Boulding's famous question 'what evolves with economic evolution?'-is characterised as existing in the routines and competences of firms (Nelson and Winter 1982). Now of course human capital, jobs 
and careers all exist inside firms, but in the neo-Schumpeterian view the analytic focus is very much on firm dynamics (changes in firm strategy, firm boundaries) and industrial dynamics (populations and networks of firms). But an evolutionary human capital approach seeks to conceive of the economy and economic evolution through the lens of knowledge as carried as a network of skills, and that human capital is the particular part of the network a person occupies, and that what changes with economic evolution is this topology of this network and the way people occupy it. Economic evolution begins with the discovery of the value of different connections in this human capital network. This provides a different view of the knowledge base of an evolving economy than the firm-centred view, and while still theoretically and empirically undeveloped, it does open windows into new types of questions. This leads to the second motivation, which is to recognise that the neoclassical human capital approach has a significant advantage in addressing questions related to the economics of labour markets, careers, education, and households. This matters, because in an evolving economy, an important factor to citizens and politics are uncertainties about employment and strategies about careers. That evolutionary economics is near silent on this limits its relevance. (Note the focus on firms and industrial dynamics has made evolutionary economics valuable in business-school syllabus, but less so elsewhere.) The third motivation is to develop a framework to connect with other social sciencesparticularly sociology, education, cultural anthropology, and cultural science (Hartley and Potts 2014) — that are closely concerned with analysis of employment, identity, households, cultural practices with respect to technology, and such like, and in particular those branches with existing evolutionary modes of analysis (e.g. Mesoudi 2011).

An evolutionary approach to human capital offers some new lines of thinking about classically complex and interdisciplinary problem domains (employment and unemployment, households, careers, universities, technological revolutions, role of government) that otherwise tend to get stuck in single-discipline low-dimensional solutions (e.g. deregulate labour markets, generously fund higher education, protect existing jobs). We propose conceptualising human capital as a complex network of connections between skills and other knowledge carriers, over which each person occupies some node, but that each node is connected to other nodes, and so human capital is simultaneously and inextricably both individual and social. It is incoherent to 
think of this nexus of knowledge as either entirely individual (neoclassical human capital) or entirely social (modern non-evolutionary sociology). By conceiving of human capital as the elements and connections of a complex knowledge network, we can ask how that network evolves, and with what causes and effect. This, then, becomes the research program of the evolutionary human capital economics.

What will this study? We can suggest only broad outlines at this early stage, but our initial framing implies the following focus. One, on the process of job separation (the beginnings of what can turn into structural unemployment) analysed through the evolutionary lens of de-coordination and revaluation of human capital networks (rather than a story of wage competition). Two, on the process of re-coordination as microentrepreneurial discovery of the value of new knowledge networks (human capital) in different contexts and with different bundling and connections, as well as the structure and logic of variation, adoption/replication and social coordination of this knowledge discovery process. Three, on the translation of existing theory and analysis from other disciplines into an evolutionary economic framework, as we have done with Callon's concept of a 'techno-economic network', Foster's (2005) higher-order network theory, and Dopfer et al's (2015) upward and downward complementarity theory. Evolutionary economists from Joseph Schumpeter to Richard Nelson have sought to understand economic evolution through an analysis of the dynamics of firms, markets and industries. Our point is that this can also be understood, using the same logic, through analysis of human capital, jobs and careers, which also evolve.

\section{References}

Arthur, M. (1994) 'The boundaryless career: a new perspective for organizational inquiry.' Journal of Organizational Behavior, 15: 295-306

Arthur, M., Rousseau, D. (1996) The Boundaryless Career. Oxford University Press: New York.

Arthur, W.B. (2009) The Nature of Technology. Free Press: New York.

Bakhshi, H., Freeman, A., Potts J. (2011) State of Uncertainty: Innovation Policy Through Experimentation. NESTA Provocation 14. NESTA: London.

Becker, G. (1964) Human Capital. National Bureau of Economic Research. New York.

Boulding, K. (1961) The Image. Ann Arbor: University of Michigan Press.

Boulding, K. (1966) 'The economics of knowledge and the knowledge of economics.' American Economic Review, 56(1/2): 1-13 
Boulding, K. (1968) 'The "National" importance of human capital', in Adams, W (Ed.) The Brain Drain, pp. 109-119

Boulding, K. (1981) Evolutionary Economics, Sage: Beverly Hills, CA.

Burton-Jones, A. Burton-Jones, A. (2012) 'Interdependencies between people and information systems in organizations', in Burton-Jones, A. \& J. Spender (eds) The Oxford Handbook of Human Capital. Oxford University Press: Oxford. Pp. 499-523

Burton-Jones, A., Spender, J. (2012) The Oxford Handbook of Human Capital. Oxford University Press: Oxford.

Callon, M. (1991) 'Techno-economic networks and irreversibility' in Laws, J. (Ed) A Sociology of Monsters, Routledge: London. Pp. 132-61.

Callon, M. (2002) "From science as an economic activity to socioeconomics of scientific research: The dynamics of emergent and consolidated technoeconomic networks' in Mirowski, P. and Sent, E. (eds.) Science Bought and Sold.. University of Chicago Press. Chicago: pp. 227-317.

Cañibano, C. \& Woolley, R. (2012) 'Towards a socio-economics of the brain drain and distributed human capital.' International Migration, 53(1): 115-130.

Coase, R. (1937) 'The nature of the firm' Economica, 4(16): 286-05.

Cowen, T. (2014) Average is over. Plume, Penguin Group: New York.

Dalton, G., Thompson, P., Price R. (1977). 'The four stages of professional careers. A new look at performance by professionals.' Organizational Dynamics, 6: 19-42.

Dopfer, K (2005) 'Evolutionary economics: a theoretical framework' in Dopfer, K. (ed) The Evolutionary Foundation of Economics. Cambridge University Press. Pp. 3-55.

Dopfer, K., Potts, J. (2004) Evolutionary realism: a new ontology for economics. Journal of Economic Methodology, 11(2): 195-212.

Dopfer, K., Potts, J., Pyka, A. (2015) 'Upward and downward complementarity: the meso core of evolutionary growth theory,' Journal of Evolutionary Economics, DOI 10.1007/s00191-015-0434-4

Elsner, W.; Heinrich, T., Scward, H. (2015) The Microeconomics of Complex Systems. Evolutionary, Institutional, Neoclassical and Complexity Perspectives. Academic Press: Elsevier.

Foster, J. (2005) 'From simplistic to complex systems in economics.' Cambridge Journal of Economics, 29: 873-92.

Foster, J. (2006) 'Why is economics not a complex systems science?' Journal of Economic Issues, XL(4): 1069-91.

Galor, O. Tsiddon, D. (1997) 'Technical progress, mobility and economic growth' American Economic Review, 87(3): 363-82.

Goldin, C., Katz, L. (2008) The Race between Education and Technology. Harvard University Press: Cambridge, MA.

Grant, R., Hayton, J. (2012) 'Interdependencies between people in organizations' in BurtonJones, A. \& Spender, J. (eds) The Oxford Handbook of Human Capital. Oxford University Press, Oxford. Pp. 403-32

Hall, D. (1996) 'Protean career of the $21^{\text {st }}$ century.' Academy of Management Executive, 10(4): $8-16$.

Hartley, J. Potts J (2014) Cultural Science: A Natural History of Stories, Demes, Knowledge and Innovation. Bloomsbury: London.

Hausmann, R., Rodrik, D. (2003) Economic development as self-discovery, Journal of Economic Development, 72: 603-33.

Hodgson, G. (1993) Economics and Evolution. Polity Press: Cambridge. 
Kapur, D., McHale, J. (2005) Give us your Best and Brightest Centre for Global Development, Cambridge, MA.

Lawson, T. (2013) 'What is this 'school' called neoclassical economics?' Cambridge Journal of Economics, 37: 947-83.

Lawson, T. (2015) 'Economics: some considerations for going forward' in Kiddey, R. (ed) Economics, the Situation is Serious, ISRF Bulletin, Issue VIII: 22-32.

Loasby, B. (2001) 'Time, knowledge and evolutionary dynamics: why connections matter.' Journal of Evolutionary Economics, 11: 393-412.

Loasby, B. (2008) 'Los microfundamentos de las capacidades organizativas', in C. Cañibano, Encinar, M.I \& Muñoz, F.F. (eds), Economía del conocimiento y la innovación: nuevas aproximaciones a una relación compleja, Pirámide, Madrid: 35-58

Loasby, B. (2012) 'Building systems.' Journal of Evolutionary Economics, 22: 833-46.

Lucas, R. (1988) On the mechanics of economic development.' Journal of Monetary Economics, 22(1): 3-42.

Mesoudi, A. (2011) Cultural Evolution: How Darwinian theory can explain human culture and synthesize the social sciences. University of Chicago Press: Chicago.

Michaels, E., Handfield-Jones, H., Axerold, A. (2001) The War for Talent. Harvard Business School Press.

Mincer, J. (1958) 'Investment in human capital and personal income distribution. Journal of Political Economy, 66(4): 281-302.

Mincer, J. (1981) 'Human capital and economic growth.' NBER.

Mirowski, P. (1989) More Heat than Light. Cambridge University Press: New York

Mirowski, P. (2009) 'Why there is (as yet) no such thing as an economics of knowledge' in Kincaid, H. \& Ross, D. (eds) The Oxford Handbook of Philosophy of Economics, Oxford University Press, New York, pp. 99-156

Mirowski, P. (2013) 'The thirteen commandments of neoliberalism.' The Utopian, June $19^{\text {th }}$. http://www.the-utopian.org/post/53360513384/the-thirteen-commandments-ofneoliberalism

Mortensen, D. (1986) 'Job search and labor market analysis'. In Ashenfelter, O., Card, D. The Handbook of Labor Economics 2. Amsterdam: North-Holland.

Muñoz, F., Encinar, M., Cañibano, C. (2011) 'On the role of intentionality in evolutionary economic change.' Structural Change and Economic Dynamics, 22: 193-203.

Nelson, R., Winter, S. (1982) An Evolutionary Theory of Economic Change, Harvard University Press: Cambridge, MA.

Penrose, E. (1959) The Theory of the Growth of the Firm, Oxford University Press: Oxford.

Pigou, A. (1920) The Economics of Welfare. Library of Economics and Liberty. http://www.econlib.org/library/NPDBooks/Pigou/pgEW.html

Potts, J. (2000) The New Evolutionary Microeconomics. Edward Elgar: Cheltenham.

Potts, J. (2010) 'Ontology in economics' in Poli, R. \& Seibt, J. (eds) Theory and Applications of Ontology: Philosophical Perspectives,

Prigogine, I. (2005) 'The rediscovery of value and the opening of economics', in Dopfer, K. (ed) The Evolutionary Foundation of Economics. Cambridge University Press: Cambridge. Pp. 61-69.

Prigoine, I., Stengers, I. (1979) La Nouvelle Alliance. Métamorphose de la Science. Collection Bibliothèque des Sciences Humaines, Gallimard, Paris.

Romer, P. (1993) 'Two strategies for economic development: Using ideas and producing ideas,' in Proceedings of the World Bank Annual Conference on Development Economics 1992, International Bank for Reconstruction of Development, Washington DC: 63-91 
Samuelson, P. (1958) 'Aspects of public expenditure theories.' Review of Economics and Statistics, 40(4): 332-8.

Saura, D. (2003) 'Autoorganización en economía: una aproximación desde la economía evolutiva.' In Rubio de Urquía, R., Vázquez, F., Muñoz, F. (eds) Procesos de Autoorganización. Instituto de Investigaciones Económicas y Sociales Francisco de Vitoria. Unión Editorial, Madrid: 225-43.

Schultz, T. (1961) 'Investment in human capital' American Economic Review, 51(1): 1-17.

Schultz, T. (1990) Restablecimiento del equilibrio económico. Los recursos humanos en una economía en proceso de modernización. Gedisa, Barcelona.

Schumpeter, J. (1942) Capitalism, Socialism and Democracy. McMillan: London.

Shackle, G ([1966] 2010) The Nature of Economic Thought. Selected Papers 1955-1964. Cambridge University Press: Cambridge.

Simon, H. (1962) 'The architecture of complexity.' Proceedings of the American Philosophical Society, 106(6): 467-82.

Tams, S., Arthur, M. (2010) 'New directions for boundaryless careers: agency and interdependence in a changing world.' Journal of Organisational Behavior, 31: 629-46.

Teece, D. (1986) 'Profiting from technological innovation: implications for integration, collaboration, licensing and public policy,' Research Policy, 15: 285-305.

Teece, D. (2012) 'Human capital, capabilities and the firm: literati, numerati, and entrepreneurs in the twenty-first-century enterprise,' Burton-Jones, A. \& J. Spender (Eds) Oxford Handbook of Human Capital. Oxford University Press: Oxford. Pp. 527-62.

Veblen, T. (1898) Why is economics not an evolutionary science?' Quarterly Journal of Economics, 12(4): 373-97.

Vona, F., Consoli, D. (2014) 'Innovation and skill dynamics: a life-cycle approach.' Industrial and Corporate Change, 24(6):1393-415.

Woolley, R. Cañibano, C. (2010) Scientific mobility and development: toward a socioeconomic conceptual framework. INGENIO Working Paper, 2010/07

Woolley, R., Cañibano, C., Tesch, J. (2016) 'A functional review of literature on research careers.' INGENIO Working Paper, 2016/05 